\title{
CARTILHA EDUCATIVA COM PROPOSTAS DE INSERÇÃO DAS LAGOAS DE FEIRA DE SANTANA NO ENSINO DE CIÊNCIAS
}

\author{
Amanda da Silva Souza ${ }^{1}$ \\ Taise Bomfim de Jesus ${ }^{2}$ \\ Leila Thaise Santana de Oliveira Santos ${ }^{3}$
}

Resumo: Considerando a relevância ambiental e contextual da abordagem das lagoas de Feira de Santana na educação básica, este estudo teve como objetivo, construir uma cartilha com propostas para inserção dessas lagoas no ensino de Ciências. Para isso, descreveu-se a situação ambiental das lagoas, e elencouse os conteúdos para a produção da cartilha. Foram construídas cinco propostas envolvendo atividades teóricas e práticas sobre a importância das lagoas, teia alimentar, meio ambiente e saúde pública, e elaboração de um projeto de recuperação de uma lagoa. Esse material apresenta potencial para ser utilizado nas escolas dado o seu aporte teórico e metodológico para a Educação Ambiental contínua, não apenas em momentos pontuais.

Palavras-chave: Lagoas; Cartilha; Educação Ambiental.

Abstract: Considering the environmental and contextual relevance of the approach to the Feira de Santana lagoons in basic education, this study aimed to build a booklet with proposals for inserting these lagoons in science education. For this, the environmental situation of the lagoons was described, and the contents for the production of the booklet were listed. Five proposals were developed involving theoretical and practical activities on the importance of the lagoons, food web, environment and public health, and the elaboration of a project for the recovery of a lagoon. This material has the potential to be used in schools given its theoretical and methodological contribution to continuous environmental education, not just in specific moments.

Keywords: Lagoons; Primer; Environmental Education.

\footnotetext{
1Universidade Estadual de Feira de Santana. E-mail: amandasouza.lic@gmail.com, Link para o Lattes: http://lattes.cnpq.br/4479678498519799

2 Universidade Estadual de Feira de Santana. E-mail: leilathaise@yahoo.com.br. Link para o Lattes: http://lattes.cnpq.br/2896839202106073

3 Universidade Estadual de Feira de Santana. E-mail taisebj@hotmail.com.

Link para o Lattes: http://lattes.cnpq.br/5058184806940165
} 


\section{Introdução}

Feira de Santana-BA é o maior entroncamento rodoviário do Norte/Nordeste, a segunda maior cidade da Bahia e localiza-se no semiárido baiano com população estimada de 619.609 habitantes (IBGE, 2020). É um município marcado pela presença de lagoas e nascentes, essa característica foi, em tempos passados, atrativa para os viajantes do sertão que reabasteciam, saciavam a sede do gado e dos próprios boiadeiros que conduziam os rebanhos. Lobão e Machado (2005) afirmam que as lagoas urbanas de Feira de Santana possuem uma importância ambiental e cultural. Essa ideia é confirmada por Franca Rocha e Nolasco (1998), que pontuam que as águas das nascentes e lagoas de Feira de Santana abasteceram a cidade e serviram de lazer para a população até a década de 1970.

Em 1970, Feira de Santana presenciou o processo de implantação do Centro Industrial do Subaé (CIS). A partir daí, a ocupação humana no município ocorreu acelerada e desordenadamente, atrelada a interesses políticos e econômicos. Somada à falta de infraestrutura urbana, os problemas socioambientais foram se agravando. Com isso, a relação que a população estabelecia com as lagoas como centro de lazer e de sobrevivência, passou a ser utilizada como áreas alternativas para residir, ou seja, as lagoas foram gradativamente aterradas e/ou servindo como depósito de lixo e de esgoto (SANTO, 2003).

A poluição das águas é um problema ambiental de caráter global que desencadeia complicações à saúde ambiental e impossibilita os usos múltiplos da água, em decorrência da não manutenção das condições básicas de qualidade da água. As principais origens de poluição hídrica são o lançamento de esgoto doméstico e industrial e, incorporação de detritos do solo à água pelo escoamento superficial (LEITE, 2004). A Agência Nacional de Águas (ANA) afirma que o esgoto sem o tratamento adequado traz prejuízos a qualidade da água na zona urbana, o que está diretamente ligado aos impactos na saúde pública, além de dificultar o abastecimento humano, balneabilidade, irrigação, e outros usos das águas.

As lagoas de Feira de Santana-BA vêm sofrendo grandes impactos ambientais ao longo dos anos, devido à expansão industrial e às ocupações irregulares nessas áreas. Os aterramentos para construção de imóveis, leva à diminuição da área, até mesmo o desaparecimento total do corpo d'água. Além disso, a disposição de lixo nas lagoas e no seu entorno, e a falta de rede de esgotos em muitos bairros compromete a qualidade das águas, tendo em vista que $35,7 \%$ dos esgotos produzidos na cidade não são coletados e nem tratados (ANA, 2017). O despejo de esgotos, nas lagoas e nascentes da cidade, é uma das principais causas de poluição desses corpos d'água.

As lagoas compreendem um ecossistema com habitats para uma diversidade de espécies. A degradação desses mananciais do município é um 
problema ambiental que traz consequências à fauna, a flora e as relações ecológicas ali estabelecidas. É importante salientar que o ser humano também é integrante dessa rede de relações, é um agente transformador do ambiente como também sujeito afetado com os problemas ambientais em se tratando, por exemplo, da saúde coletiva.

As lagoas de Feira de Santana estão fortemente ligadas à constituição do próprio município, sendo assim, pode ser considerado um patrimônio cultural e histórico, além da sua importância ambiental e social. Atualmente, o cenário das lagoas da cidade é caracterizado por problemas que se intensificam cada vez mais, e muitas vezes são negligenciados pelo poder público como também pela educação. A abordagem das lagoas no ensino se torna necessária para a formação crítica dos alunos, visto que muitos deles moram em bairros que contemplam as lagoas e vivem de perto essa realidade. Outros, vivem nesses bairros, mas não percebem os problemas ambientais ali presentes. Surge então, a importância de trabalhar conteúdos que contextualizem com a realidade do estudante, assim, as lagoas tornam-se cenários de aprendizagem em uma perspectiva contextual.

A educação deve transcender os muros da escola, os conteúdos devem ser abordados de forma contextualizada, pois o aluno é um ser social e a educação deve promover o exercício da cidadania. A contextualização contribui para um ensino de ciências significativo, pois, dessa forma, os alunos percebem o sentido do que aprendem na escola em suas vidas. Assim, auxilia na resolução de problemas do dia a dia, tomada de decisões de forma autônoma e intervenção na sua realidade (PRUDÉNCIO; GUIMARÃES, 2017).

O trabalho de Nascimento et al. (2020) retrata a importância do uso de cartilhas como materiais paradidáticos para complementar abordagem de temas regionais, tendo em vista que muitas vezes, o livro didático possui abordagem limitada. O presente trabalho teve como objetivo construir uma cartilha com propostas para inserção das lagoas urbanas de Feira de Santana-BA e apresentá-lo como material paradidático, alternativo e/ou complementar, para o ensino de Ciências.

A ideia desse material está relacionada a dois objetivos do Plano Municipal de Feira de Santana. Segundo Feira de Santana (2012 p. 152-159) esses objetivos consistem em:

Produzir materiais didáticos alusivos ao meio ambiente, com o enfoque prioritariamente nos problemas ambientais de Feira de Santana, durante a vigência do plano [...].

[...] Inserir, transversalmente, a temática Meio Ambiente nas propostas curriculares e nos documentos pedagógicos dos sistemas de ensino no município de Feira de Santana, norteando assim, o procedimento metodológico e interdisciplinar, a partir do primeiro ano de aprovação do Plano. 
O uso de uma cartilha que contemple problemas sociais e ambientais contextualizadamente, pode promover uma ampliação na visão dos alunos frente a uma realidade. Ao abordar problemas que fazem parte de seu contexto social, os estudantes podem conhecer as questões socioambientais, sensibilizar-se à situação e desenvolver um pensamento crítico que influencia em sua conduta humana.

\section{Material e métodos}

Para a construção da cartilha foi necessário realizar a caracterização da situação ambiental das lagoas de Feira de Santana, através da pesquisa bibliográfica e das visitas de campo. Para a descrição ambiental das lagoas de Feira de Santana, foram escolhidas as principais lagoas urbanas da cidade: Lagoa Grande, Lagoa Salgada, Lagoa da Taboa, Lagoa Subaé, Lagoa do Prato Raso e Lagoa da Pindoba.

Foram realizadas pesquisas sobre temáticas como aporte teórico para a construção da cartilha, tais como: o ensino de ciências, Educação Ambiental, doenças de veiculação hídrica, história de Feira de Santana e os problemas ambientais associados às lagoas urbanas. Nessa busca de literatura foram definidas as ideias sociointeracionistas de Vygotsky (VYGOTSKY,1991; IVIC, 2010), aprendizagem significativa de Ausubel (AUSUBEL, 1980 apud VASCONCELOS et al., 2003) e a reflexão crítica no contexto do aluno proposto por Paulo Freire (FREIRE, 1996), como pressupostos teóricos e metodológicos para o desenvolvimento das propostas sobre as lagoas junto aos conteúdos de ciências.

Foram analisados os Parâmetros Nacionais Curriculares para o ensino de ciências, Parâmetros Curriculares Nacionais do meio ambiente e a Base Nacional Comum Curricular, para a escolha dos documentos oficiais para nortear a produção do material paradidático.

A partir disso iniciou-se o planejamento da construção do material didático, definindo os professores de ciências da educação básica como o público-alvo, e o objetivo da cartilha, como sendo um material de apoio para o planejamento de aulas que contemplem as lagoas de Feira de Santana. Posteriormente, foi realizado um levantamento de temáticas e conteúdo que poderiam abordar as lagoas de Feira de Santana.

Para essa construção adotaram-se quatro estratégias orientadoras de Machado e Matos (2015) para a elaboração dos recursos didáticos. A primeira estratégia é de planejamento que foi iniciada com as visitas de campo, de modo a conhecer o contexto em que serão aplicados os conteúdos. A segunda, é a estratégia de linguagem, foi adotada uma linguagem objetiva e direta. Na cartilha consta informações de forma didática e ilustrada para facilitar a compreensão apropriando de uma linguagem simples, metodologia adotada também por Rabelo et al. (2015). O layout e imagens da cartilha foram realizados no Word 2013, PowerPoint 2013 e no Programa Business Model Canvas. A terceira é a 
estratégia hipertextual, que se caracteriza por organizar as propostas de ensino, de modo a estabelecer conexões entre os assuntos e temáticas selecionadas, buscando assimilar o que já conhece com as informações novas. A quarta é a estratégia cooperativa, diz respeito às propostas da cartilha, caracterizada por atividades que envolvem os alunos através da interação e aprendizagem coletiva e, a correlação dos conteúdos trabalhados em sala com as lagoas.

\section{Resultados e discussão}

As lagoas urbanas de Feira de Santana passaram pela sua total hegemonia no espaço, comparado às construções residenciais e comerciais, até a sua completa supressão/aterramento, com a expansão urbano/industrial. Segundo Neto e Fracalanza (2003), no período de 1992 a 1995, Feira de Santana possuía 48 lagoas. Atualmente existem cerca de 20 lagoas no perímetro urbano, destacando-se seis como principais: Lagoa Grande, Lagoa Salgada, Lagoa Subaé, Lagoa da Pindoba, Lagoa da Taboa e Lagoa do Prato Raso.

Os principais problemas encontrados nesses mananciais foram as ocupações irregulares no entorno e dentro das próprias lagoas, e a falta de esgotamento sanitário adequado nos bairros adjacentes, que desencadeia 0 despejo do esgoto nos corpos d'águas. Outros problemas como, mineração de argila e queimadas, acometem a Lagoa Salgada. A proliferação de macrófitas na Lagoa da Pindoba e na Lagoa Subaé, corresponde a um indicativo de eutrofização dos mananciais.

A cartilha foi elaborada com base nos PCN do ensino de ciências naturais, posteriormente as propostas foram encaixadas nas unidades temáticas da BNCC tomando como base sua ideia central. Foi realizada a adequação das propostas da cartilha às unidades temáticas da BNCC, pois oficialmente esse é o novo documento com as orientações e padronizações a serem seguidas pela educação básica. A cartilha construída nesse trabalho, contempla duas unidades temáticas estabelecidas pelo documento, entretanto, optou-se por seguir as orientações presentes nos Parâmetros Nacionais Curriculares que permitem uma abordagem mais ampla, interdisciplinar e contextualizada. A ideia da cartilha é justamente para que os professores não se limitem apenas às propostas da BNCC, e poderem estender as abordagens dos conteúdos para além dos muros da escola, valorizando o contexto do aluno no ensino de ciências.

Os PCN do ensino de ciências estabelecem algumas capacidades que o aluno do ensino fundamental II deve desenvolver no final dessa modalidade. Brasil (1998, p. 33) pontua algumas dessas capacidades:

Compreender a natureza como um todo dinâmico e o ser humano em sociedade como agente de transformações do mundo que vive em relação essencial com os demais seres vivos e outros componentes do ambiente [...] Formular questões, diagnosticar e propor soluções para problemas reais a partir de 
elementos das ciências naturais, colocando em prática conceitos, procedimentos e atitudes desenvolvidos no aprendizado escolar [...] e compreender a saúde pessoal, social e ambiental como bens individuais e coletivos que devem ser promovidos pela ação de diferentes agentes [...].

Essas capacidades foram tomadas como instrumento basilar para a elaboração das propostas de inserção das lagoas de Feira de Santana-BA como temática transversal aos conteúdos de ciências.

A cartilha apresenta 5 propostas de inserção das lagoas urbanas de Feira de Santana no ensino de ciências:

\section{Proposta 1: Lagoas urbanas de Feira de Santana e seus problemas ambientais}

A primeira proposta é promover a discussão sobre a importância das lagoas de Feira de Santana e seus problemas ambientais (Figura 1).
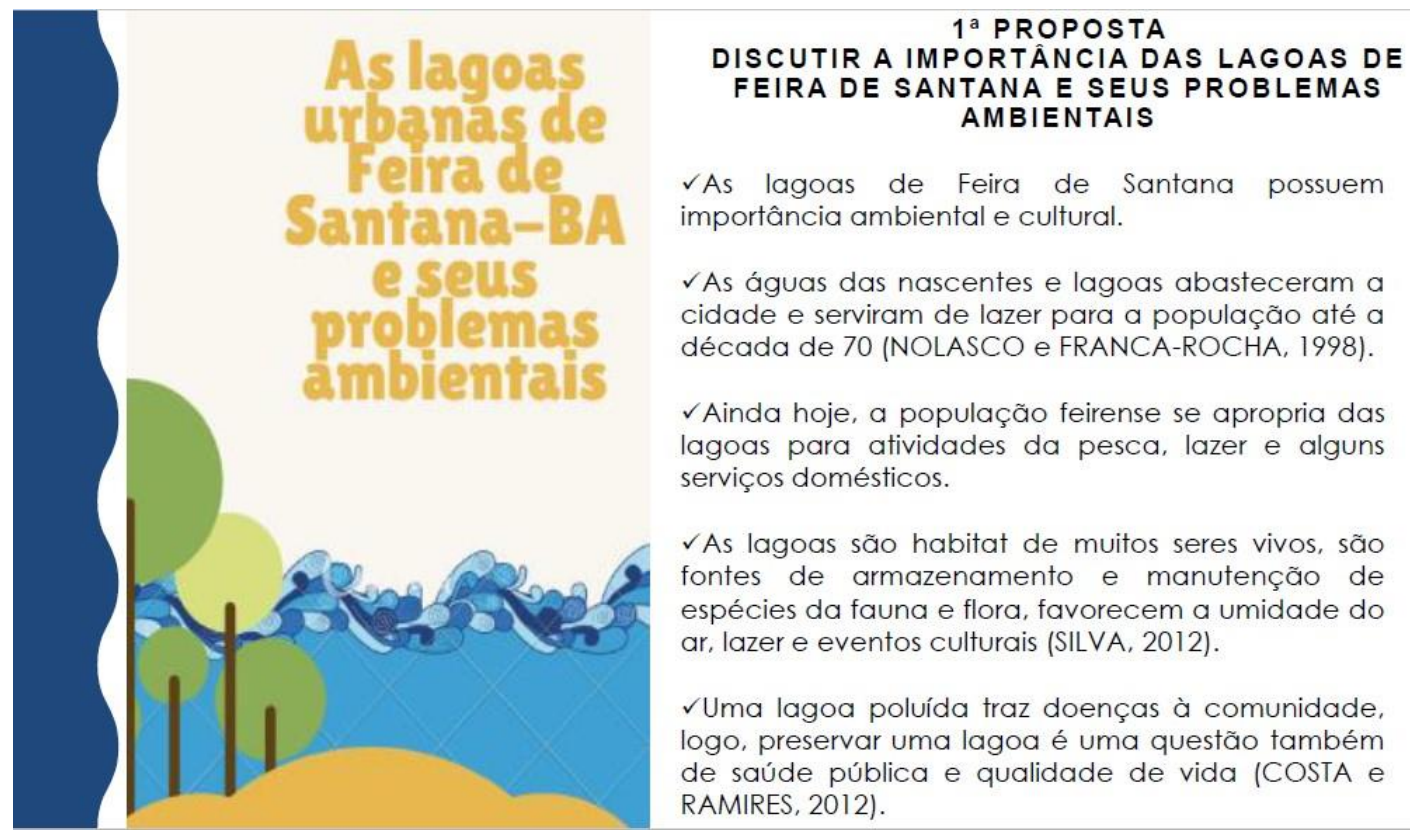

Figura 1: Breve apresentação da cartilha, destacando a importância de trabalhar as lagoas urbanas de Feira de Santana-BA no ensino de ciências no ensino fundamental II, página 09.

Fonte: Próprias autoras.

$\mathrm{Na}$ cartilha consta com um referencial teórico sobre como as lagoas fazem parte da história da cidade e da cultura da população feirense, além de seus aspectos biológicos e sociais em se tratando de saúde pública. A população do entorno de uma lagoa poluída torna-se vulnerável a contaminar-se com vetores de doenças de veiculação hídrica. Ainda nesse aspecto, é válido considerar a discussão sobre as ocupações irregulares no entorno e dentro da própria lagoa, que provocam 0 aterramento desses mananciais para as 
expansões residencial, comercial e industrial, causando assim, a degradação das lagoas.

Essa proposta permite que o professor explore a percepção dos alunos em relação ao meio ambiente, tomado como referência as lagoas que estão localizadas nos seus bairros, na escola e/ou que eles conhecem. Para Vygotsky (1988), a percepção de algo se dá quando o sujeito lhe atribui significado, isso ocorre desde a infância. Partindo desse pressuposto, a discussão sobre as lagoas permite abordar alguns valores como responsabilidade coletiva e cidadania, tendo como princípio a sensibilização e compreensão dos problemas, em uma perspectiva sistêmica. A proposta 1 permite que os alunos percebam 0 ambiente em que vive e possa enxergar as lagoas, de modo ao estabelecer um sentimento de pertencimento pelo seu valor cultural e histórico.

Muitas vezes, as pessoas desconhecem a existência das lagoas intermitentes da cidade, nesse momento, cabe ao professor de ciências trabalhar em conjunto com o professor de geografia. Por exemplo, no sentido de abordar o conceito de lagoa e seu regime de água, índice pluviométrico, relevo e distribuição dos solos e vegetação. Isso influencia na forma do aluno pensar sobre esse ambiente, pois grande parte das lagoas de Feira de Santana só aparecem em períodos de cheia e muitos acabam desconhecendo que ali existe uma lagoa. Essa percepção favorece as ocupações espontâneas nesses locais, além dos depósitos de lixo, entulhos e esgotos.

Essa proposta pode ser trabalhada no ensino fundamental II, ao abordar o conteúdo Água no ensino de ciências, estabelecido pelos PCN. Com a BNCC promulgada, não existe mais um conteúdo específico sobre água, entretanto, é possível conduzir essa abordagem na unidade temática Matéria e Energia, tendo em vista que as lagoas são recursos naturais, e a água é considerada matéria e fonte de energia. É importante que a escola atribua significados à questão ambiental, de modo que o aluno compreenda o ambiente trazendo uma abordagem contextualizada, permitindo que o aluno estabeleça ligações entre o novo e o que já conhece.

$\mathrm{Na}$ descrição dessa proposta há sugestões de diversas formas que o professor poderá promover essa discussão. Uma delas é a solicitação aos alunos de realizarem uma pesquisa prévia sobre as lagoas de Feira de Santana, trazendo aspectos biológicos, históricos e geográficos das lagoas. A consulta pode ser diversa, a partir de artigos, notícias, reportagens e outros materiais bibliográficos que facilitem a discussão em sala posteriormente.

Fazer com os alunos percebam os problemas ambientais de sua realidade, e, sobretudo, se ver como parte integrante desse sistema, é fundamental para a construção de valores e paradigmas que norteiam suas ações, visto que a forma de observar o mundo define suas práticas. Além disso, trazer a ideia interdisciplinar é importante, para que os alunos ampliem seu olhar frente aos problemas ambientais e possam enxergar que o ambiente é complexo e não se resume a apenas uma área de conhecimento. A interdisciplinaridade é fundamental na educação, para superar a abordagem fragmentada do 
conhecimento e da visão de mundo. Jacobi (2003) afirma serem necessárias reflexões menos lineares, produzindo assim um diálogo entre os saberes e as práticas coletivas. Essa abordagem cria identidades, valores comuns e ações solidárias diante da reapropriação da natureza.

Sugere-se também um trabalho com o uso de músicas que trazem um retrato sobre os problemas ambientais, instigando o aluno analisar criticamente e fazer um diálogo com a realidade ambiental das lagoas de Feira de Santana. Camargo (2014) defende a importância da ludicidade no processo de transposição dos conteúdos referentes à Educação Ambiental. Ainda nesse sentido, Abílio (2008) aponta que "as atividades lúdicas não se restringem ao jogo e à brincadeira, mas incluem atividades que possibilitam momentos de prazer, entrega e integração dos envolvidos".

Além da discussão, há uma sugestão para os alunos construírem uma arte ambiental expressando os problemas ambientais das lagoas. Trabalhar a arte com ciências, no processo de Educação Ambiental, permite que o aluno desenvolva sua sensibilidade, criatividade, explore sua expressividade traduzindo sua forma de ver, sentir e estar no mundo. O aluno deve se sentir livre para expressar seus pensamentos, pode se manifestar com outras formas artísticas, tais como desenhos, pinturas etc. O senso estético é um modo contínuo e eficaz de compreender o mundo e agir sobre ele (SANTOS et al., 2015). Freire (1996 p. 21) afirma que "ensinar não é transferir conhecimento, mas criar as possibilidades para a sua produção ou a sua construção".

\section{Proposta 2: Visita à lagoa mais próxima da escola}

A proposta 2 é caracterizada por uma visita à lagoa mais próxima da escola como atividade de campo em ciências, essa atividade é definida como aquela que permite que os alunos se desloquem para um espaço diferente daquele que compreende a escola (Figura 2, próxima página).

As atividades de campo no ensino de ciências consistem em uma estratégia de ensino que permitem trabalhar as relações entre os seres vivos presentes naquele ambiente, destacando a presença do homem no processo de interação com as outras espécies e permite ainda explorar aspectos naturais, sociais, históricos e culturais (VIVEIRO; DINIZ, 2009).

As atividades de campo possibilitam que o aluno estabeleça um contato direto com o ambiente e permitem a interação com as situações reais, além disso, desperta os sentidos e refletir sobre a teoria e prática (OLIVEIRA et al., 2012). A visita às lagoas é uma atividade contextual, porque corresponde a um ambiente próximo da escola ou da residência dos alunos. Esse trabalho de campo possibilitará ao estudante um sentimento de pertencimento por tratar de sua realidade, ou ainda despertar uma percepção e sensibilização quanto às questões ambientais que até então poderiam estar despercebidas. 


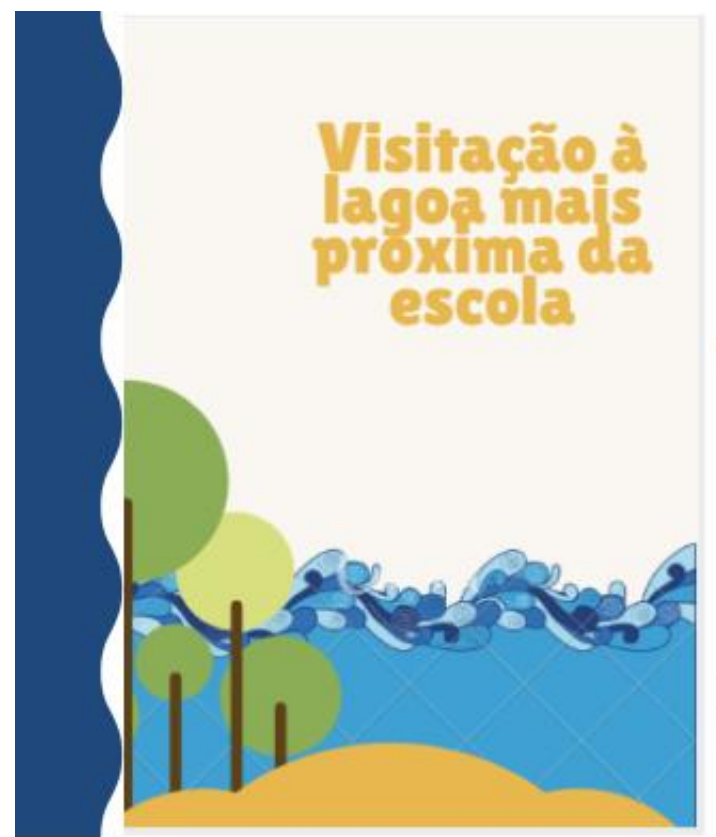

\section{2 a PROPOSTA \\ VISITA À LAGOA MAIS PRÓXIMA DA ESCOLA}

A proposta é caracterizada por uma visitação à lagoa mais próxima da escola, essa visita levará o aluno a compreender o ambiente lacustre a partir

de um olhar crítico imbuído de conteúdos conceituais e procedimentais do ensino de Ciências.
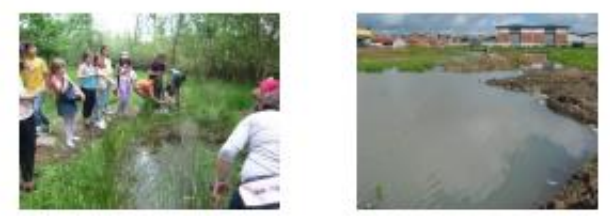

O professor poderá dividir a turma em grupos pequenos para que as discussões entre eles ampliem seu pensamento crítico com relação aos problemas ambientais da lagoa.

Figura 2: Breve apresentação da cartilha, destacando a importância de trabalhar as lagoas urbanas de Feira de Santana-BA no ensino de ciências no ensino fundamental II, página 17 da cartilha.

Fonte: Próprias autoras.

Uma sugestão para auxiliar a observação dos alunos no campo é o professor elaborar um roteiro de perguntas (Figura 3), na cartilha está um exemplo que o professor pode se basear, mas não necessariamente devem ser estas ou somente estas perguntas orientadoras.

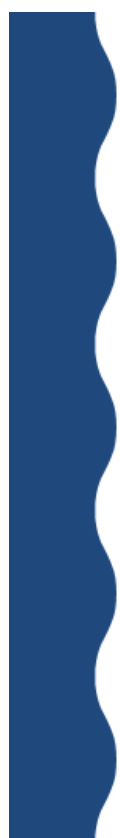

\section{2 a PROPOSTA \\ VISITA À LAGOA MAIS PRÓXIMA DA ESCOLA}

É fundamental que o professor elabore um roteiro de perguntas para orientar as observações dos alunos, por exemplo:

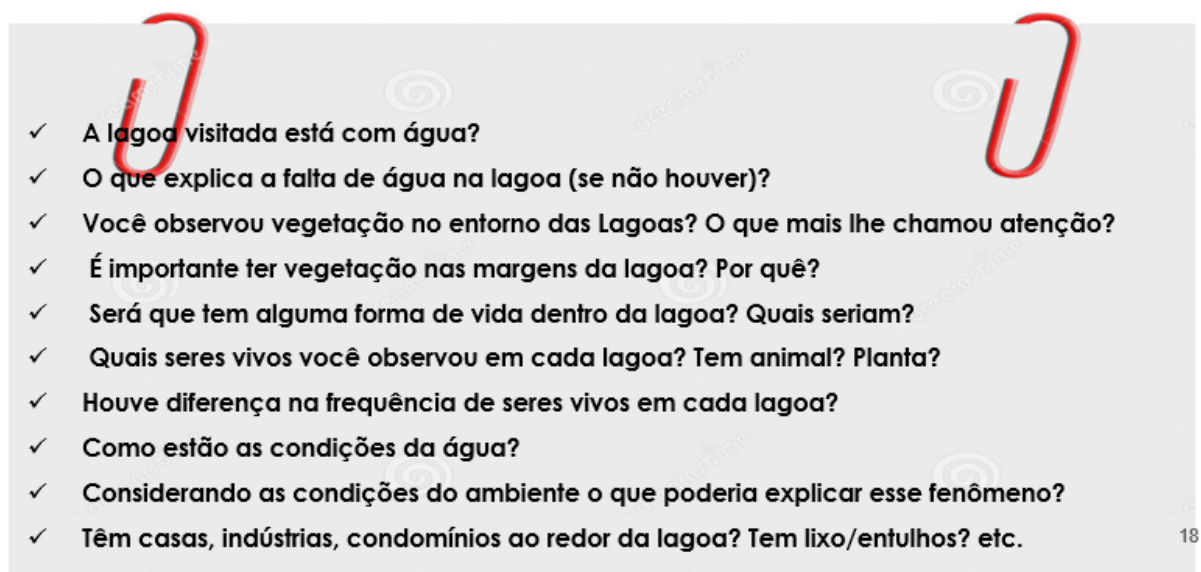

Figura 3: Breve apresentação da cartilha, destacando a importância de trabalhar as lagoas urbanas de Feira de Santana-BA no ensino de ciências no ensino fundamental II, página 18 da cartilha.

Fonte: Próprias autoras. 
Essas perguntas são para instigar o aluno a perceber as inter-relações dos elementos físicos, sociais e biológicos, bem como conduzir a indagações e elaborar hipóteses com base em alguns conteúdos do ensino de Ciências. Tais como, solo, água, seres vivos, relações ecológicas e a interferência do ser humano na dinâmica dos ambientes como prescrito nos PCN, mas também pode contemplar a unidade temática Matéria e Energia considerando a água como recurso natural e matéria. É importante deixar claro que as perguntas são apenas para orientar e que eles devem explorar ainda mais suas percepções relacionadas ao ambiente, identificar os problemas ambientais e relacionar com os conteúdos trabalhados tanto na disciplina de ciências quanto nas outras disciplinas.

O registro e discussão em grupo das observações na lagoa permitem explorar os conteúdos conceituais de aprendizagem quando eles conduzem referência aos assuntos nas disciplinas. A própria observação e registro atende ao conteúdo procedimental, contemplando as capacidades motoras e cognitivas como observar as lagoas, analisar e registrar o ambiente. Nessa atividade é possível ainda, a reflexão e discussão dos problemas ambientais observados com os colegas contemplando ao objetivo atitudinal. Os conteúdos conceituais, procedimentais e atitudinais são importantes para o processo de Educação Ambiental. Zabala (1998) traz a amplitude do termo conteúdo, comumente atribuído apenas aos conhecimentos das disciplinas clássicas envolvendo nomes, conceitos, princípios, enunciados e teoremas, onde se tem um sentido disciplinar e de caráter cognitivo. Considerando a educação com seu papel de formação integral do aluno, é preciso desenvolver além das capacidades cognitivas, capacidades motoras (procedimentos), relação interpessoal e de inserção social (atitudes).

Na visita à lagoa, sugere-se também na cartilha, uma pesquisa de campo com os moradores do entorno com objetivo de realizar um etnoinventário biológico. Essa atividade corresponde a um levantamento dos grupos faunísticos que eram observados na lagoa e que atualmente já não se veem com tanta frequência ou não se veem mais. Assim, evidencia a influência da degradação das lagoas na diversidade biológica. Essa intervenção é procedimental e atitudinal, pois requer métodos e habilidades para a realização da pesquisa, e permite também trabalhar em equipe e cooperar com o grupo. Assim, possibilita que $o$ aluno atribua valores à biodiversidade e emita um juízo sobre as suas condutas no sentido de responsabilidade coletiva.

\section{Proposta 3: Teia alimentar}

A proposta 3 tem como tema geral trabalhar a teia alimentar, a qual se enquadra na unidade temática Vida e evolução estabelecida pela BNCC (Figura 4). 

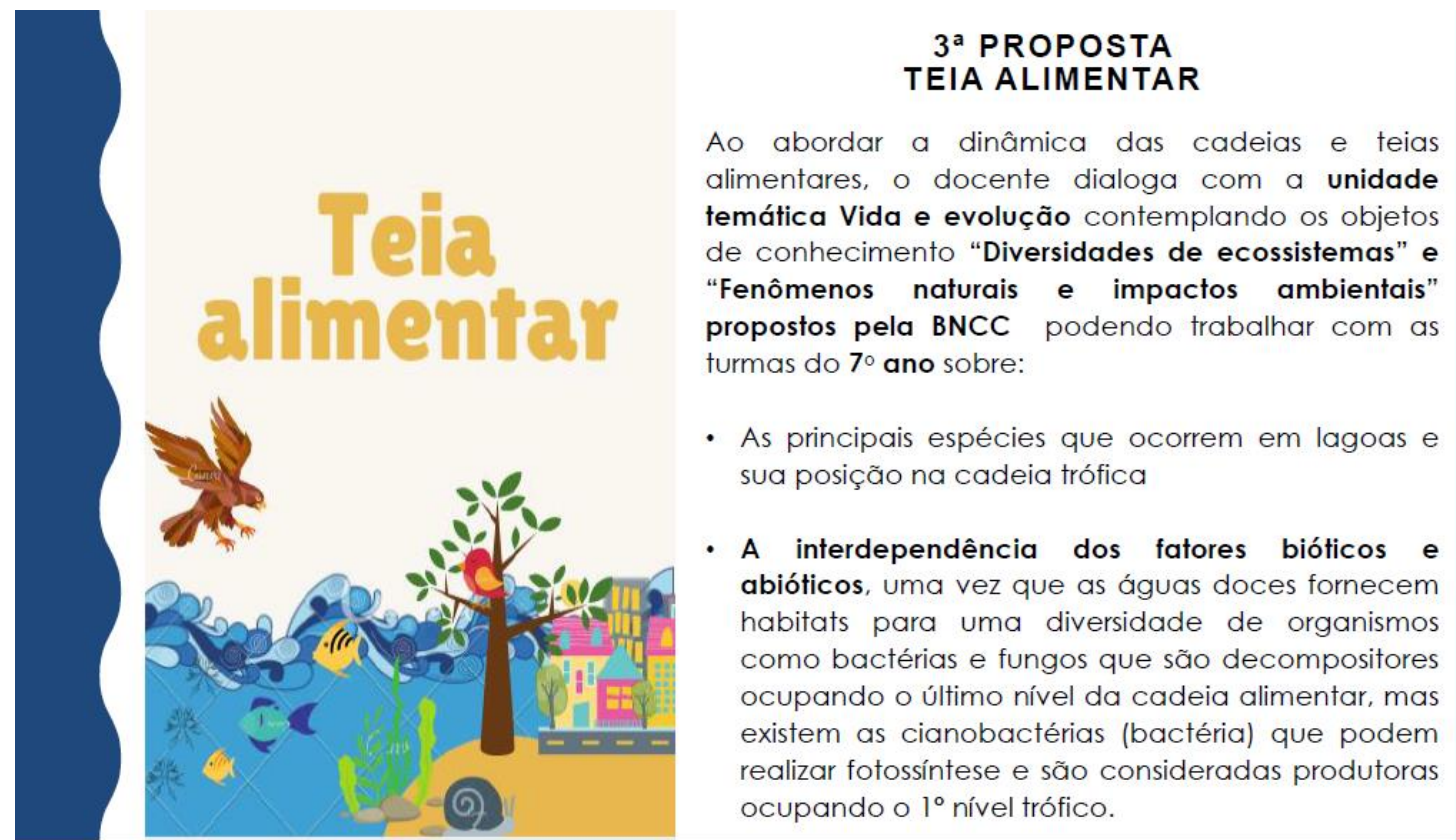

Figura 4: Breve apresentação da cartilha, destacando a importância de trabalhar as lagoas urbanas de Feira de Santana-BA no ensino de ciências no ensino fundamental II, página 20 da cartilha.

Fonte: Próprias autoras.

A ideia de trabalhar a proposta 3 seria trazer um exemplo de cadeia alimentar que pode ser observada nas lagoas. Esses mananciais são ecossistemas que abrangem relações com o meio biótico e abiótico. Além disso, é importante ressaltar que na teia de relações a presença do homem é marcante, pois existe uma interdependência entre os fatores biológicos e sociais. Muitas vezes, o aspecto social não é considerado devido ao ser humano não se considerar como elemento da natureza, mas sim como meramente um observador e/ou explorar dela. Essa percepção de ambiente leva a um argumento antropocêntrico (quando o ser humano se coloca como a espécie mais importante em detrimento aos outros seres vivos), trabalhar essa vertente consiste em um dos princípios éticos da Educação Ambiental (REIGOTA, 2001).

A origem da crise da biodiversidade está na pressão exercida pelo ser humano, tais como: caça predatória, destruição de habitat, ciclos biogeoquímicos alterados, poluição e exploração de recursos naturais de forma desenfreada. Tais ações ocasionam a diminuição da diversidade genética, tamanho de populações e extinção de espécies (PRIMACK; RODRIGUES 2001). Sendo assim, sugere-se trabalhar a diversidade biológica das lagoas, dado que são habitats para seres vivos, entretanto, com sua degradação ambiental já não se percebe tanto essa biodiversidade. Daí a importância de trabalhar o homem como agente modificador do ambiente e como isso afeta as relações ecológicas.

Com a pesquisa de campo sugerida na proposta 2, é possível dialogar com a proposta 3 , o levantamento de espécies com base nos conhecimentos dos moradores do entorno da lagoa, permite trabalhar uma Educação Ambiental pautada na preservação da diversidade biológica. A extinção vem se tornando 
um problema crescente no modelo de sociedade vigente como pontuam os autores Peroni e Hernandez (2011).

Os problemas ambientais são problemas sistêmicos, ou seja, estão interligados e interdependentes, e não podem ser entendidos isoladamente, por exemplo, a escassez de recursos e a degradação do ambiente combinam-se com populações em rápida expansão (CAPRA, 2006).

\section{Proposta 4: Meio ambiente e saúde}

A quarta proposta da cartilha é trabalhar meio ambiente e saúde pública. Dessa forma, contempla o objeto de conhecimento proposto pela BNCC, Programas e indicadores de saúde pública, da unidade temática "Vida e evolução" (Figura 5). Embora só conste essa abordagem na BNCC, é importante que o professor não limite a discussão apenas aos programas e indicadores de saúde. É importante promover uma ampliação nas discussões com os alunos, pensando o ambiente como sendo complexo e os fatores envolvidos para a sua qualidade, sejam políticos, sociais, históricos e/ou biológicos. As lagoas de Feira de Santana tornam-se um exemplo contextual para trabalhar a inter-relação entre os aspectos biológicos e sociais em se tratando de meio ambiente e saúde. Essas discussões podem possibilitar o aluno a pensar criticamente a respeito do saneamento básico do município, impactos ambientais e saúde coletiva.

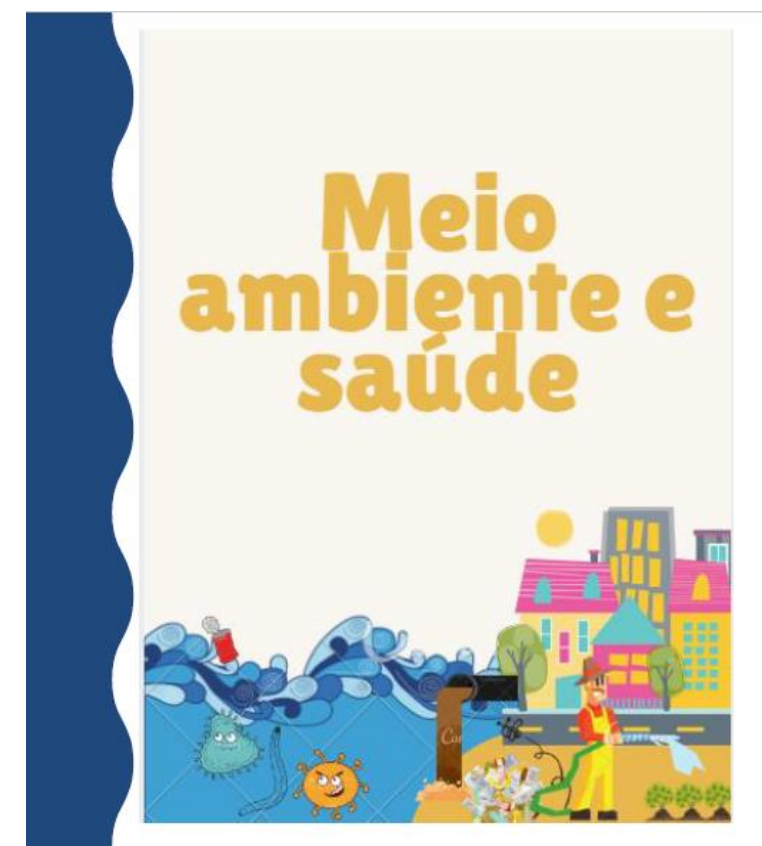

\section{4 a PROPOSTA MEIO AMBIENTE E SAÚDE}

Essa proposta pode ser trabalhada no $7^{\circ}$ ano
atendendo ao objeto de conhecimento proposto pela BNCC "Programas e indicadores de saúde pública" da unidade temática "Vida e evolução" ao abordar aspectos do meio ambiente relacionados à saúde pública, não somente como sendo um equilíbrio dinâmico a nível individual (corpo), mas como um bem coletivo (saúde de forma abrangente).

Assim, as lagoas de Feira de Santana-BA tornam-se um exemplo contextual para trabalhar as relações entre ambiente e saúde, estimulando os alunos a pensar em saneamento básico, impactos ambientais e saúde coletiva.

Figura 5: Breve apresentação da cartilha, destacando a importância de trabalhar as lagoas urbanas de Feira de Santana-BA no ensino de ciências no ensino fundamental II, página 25 da cartilha.

Fonte: Próprias autoras. 
Os materiais educativos com foco em educação e saúde devem contemplar informações contextualizadas, de modo que o aluno reflita e tome decisões por parte do grupo envolvido (SCHALL; DINIZ, 2001). Na perspectiva da Educação Ambiental, a proposta 4 permite trabalhar o saber ambiental pautado em valores éticos. Na prática, o que é de todos acaba sendo de ninguém, haja vista que a responsabilidade coletiva se torna submersa, entretanto, é preciso entender a importância da ética ambiental nas ações antrópicas. Layrargues (2000) questiona a exploração dos recursos naturais, que direito temos de explorá-los? De poluir o ar que todos respiram ou a água que todos bebem?

Uma das sugestões descritas na cartilha é abordar sobre as doenças de veiculação hídrica associadas ao baixo nível de saneamento básico. Alguns platelmintos e nematódeos são parasitas e causadores de doenças no ser humano, por exemplo, a esquistossomose, ascaridíase e ancilostomose. As lagoas de Feira de Santana são receptoras de esgotos provenientes de residências de forma direta ou indireta via fossas, considerando que a maioria das lagoas surge do afloramento das águas do lençol freático. Além das verminoses, existe também a contaminação bacteriana, foram detectados níveis muito altos de coliformes totais e termotolerantes nas águas das Lagoas Salgada e Grande durante o ano de 2016 e 2017, em um trabalho de monitoramento da qualidade da água.

As comunidades do entorno das lagoas, muitas vezes se apropriam de suas águas para irrigar hortaliças, lavar os utensílios domésticos, pescar e realizar atividades recreativas. Para o consumo humano, a água deve ser isenta da presença de coliformes totais em $100 \mathrm{ml}$ seguindo o padrão microbiológico de potabilidade da água. Considerando os usos múltiplos da água das lagoas que se enquadra na Classe II (BRASIL, 2005), a água deve conter no máximo 1000 NMP de coliformes termotolerantes, no entanto, nas amostras coletadas da Lagoa Salgada apresentaram de 1300 a $\geq 16.000 .000$ NMP e da Lagoa Grande de 20.000 a $\geq 1.600 .000$ NMP.

A metodologia sugerida para trabalhar essas doenças consiste em seminários. Nesse trabalho, o aluno poderia pesquisar sobre o assunto e trazer o conteúdo de ciclo de vida dos nematódeos, platelmintos e protozoários, e as formas de transmissão. Desse modo, daria ênfase às lagoas como ambientes vulneráveis para transmissão de doenças causadas por verminoses e microrganismos patogênicos. Nesse seminário, é importante que o aluno traga notícias sobre a incidência da doença no mundo, no Brasil e na cidade de Feira de Santana-BA e, também informações sobre as formas de contato que as pessoas têm com as lagoas da cidade. Somado a isso, seria interessante também a discussão sobre os bairros que não tem acesso ao saneamento básico, as causas dessa situação ambiental e suas implicações. Essa atividade dialoga com as tecnologias educacionais (TE), pois os alunos poderiam consultar os dados do Departamento de Informática do SUS (DataSUS) e do Instituto Brasileiro de Geografia e Estatística (IBGE). 
No item "Curiosidades" da cartilha (Figura 6) há um relato da pesquisa de Nunes (2012) que está relacionado com a temática meio ambiente e saúde. Foram verificados metais pesados presentes no tecido muscular de peixes presentes na Lagoa Salgada, Feira de Santana-BA, em concentrações que ultrapassam o valor máximo permitido para o consumo humano. Esses dados são uma ponte para trabalhar os impactos à saúde humana devido a uma questão cultural e econômica em Feira de Santana, dado que muitos moradores costumam pescar tanto nas lagoas perenes como nas temporárias. A pesca traz renda para a comunidade circunvizinha, e consiste em uma atividade recreativa, onde muitos utilizam os peixes para o próprio consumo humano.
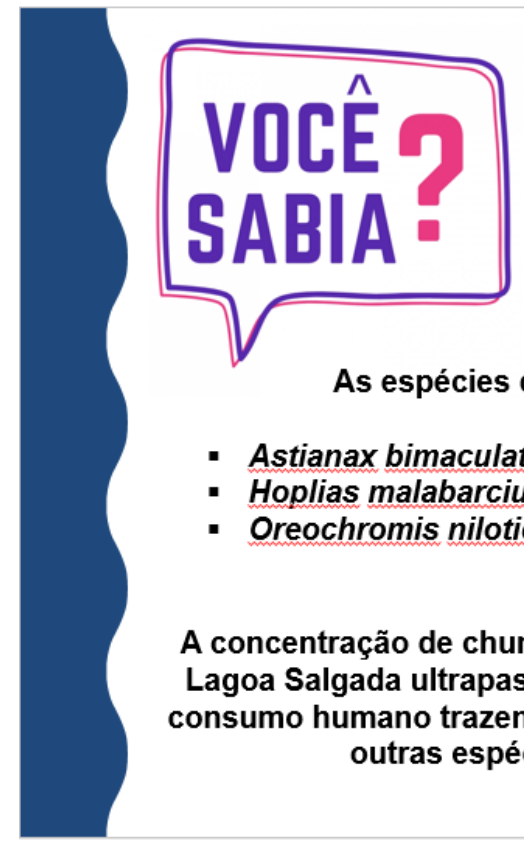

Foi detectada a presença de metais pesados (Mg, d, $\mathrm{Cr}$, Cu e $\mathrm{Pb}$ ) no tecido muscular de peixes presentes na Lagoa Salgada em Feira de Santana

As espécies de peixes contaminadas foram:

- Astianax bimaculatus (Linnaeus, 1758)

- Hoplias malabarcius (Bloch, 1974)

- Oreochromis niloticus (Linnaeus, 1757)

A concentração de chumbo encontrada nessas espécies da Lagoa Salgada ultrapassa o valor máximo permitido para o consumo humano trazendo riscos à saúde, assim como afeta outras espécies da cadeia alimentar.

Figura 6: Breve apresentação da cartilha, destacando o item de curiosidades, página 30 da cartilha.

Fonte: Próprias autoras.

Alimentar-se de peixes contaminados por metais pesados traz uma série de complicações ao funcionamento do organismo, tendo em vista que são substâncias bioacumuladoras, perpassa toda a cadeia alimentar e interfere outras formas de vida também. Seria uma vertente a se discutir nas aulas de ciências ao trabalhar, por exemplo, o corpo humano. Poderia destacar os efeitos dos metais pesados nos sistemas metabólicos, bem como compreender 0 ambiente em uma perspectiva mais complexa em se tratando de elementos que se bioacumulam e transitam na cadeia alimentar. Isso permite refletir os impactos mais globais, não apenas a saúde individual, como também a saúde coletiva, biodiversidade e gerações futuras.

Essa discussão promove a percepção que o processo educativo não se restringe ao aprendizado individualizado dos conteúdos escolares, mas na relação de um com o outro e com o mundo, afirmando que a educação se dá na relação (BRASIL, 2004). Isso segue o que se propõe a educação em saúde, 
quando compreendida de forma abrangente relacionando cidadania, qualidade de vida e o papel de cada indivíduo para promoção da sua própria saúde e da comunidade onde se insere. Desse modo, é possível que o aluno perceba os múltiplos fatores associados ao ambiente que influencia na saúde, dado que a sua manutenção depende também da ação como cidadão crítico e participativo (MARTINS et al., 2012).

Quando se fala em tratamento de doenças é comum associar a apenas fazer o uso de remédios, entretanto, existem algumas doenças tais como as de veiculação hídrica que o tratamento deve ser considerado seguindo a via de resolução da origem e causas. Martins, Santos e El-Hani (2012) citam as mudanças comportamentais, educação sanitária e saneamento básico. Essas medidas são fundamentais para se discutir qualidade ambiental, no contexto dos bairros de Feira de Santana que não dispõem de rede de esgotos e coleta de lixo regularmente. Feira de Santana é a segunda maior cidade da Bahia e ocupa - $65^{\circ}$ lugar no ranking de esgotamento sanitário adequado comparando a outros municípios (IBGE, 2010). De acordo com estudos sobre esgotamento sanitário inadequado e impacto na saúde da população realizados em 2011, pelo Instituto Trata Brasil, Feira de Santana estava entre as 10 cidades com maiores taxas de internações por diarreia representadas por crianças com $73,3 \%$.

As habitações do entorno das lagoas estão sujeitas às inundações $e$ alagamentos, isso tem se tornando um impasse para a qualidade de vida da população, quando se trata de não ter uma moradia digna, como também pela vulnerabilidade ao contágio de doenças. IBGE (2012) afirma que em países de clima quente, as doenças de veiculação hídrica ocorrem tanto nos períodos de cheia e seca, sendo que na estação chuvosa elas se destacam devido às inundações. O Instituto cita ainda os riscos de ocorrência dessas doenças, como a cólera, giardíase, infecção por Shiguella, febre tifoide e infecção por Escherichia coli. No Brasil, as doenças de transmissão feco-oral, principalmente as diarreias, correspondem mais de $80 \%$ das doenças relacionadas ao saneamento ambiental inadequado.

\section{Proposta final: vamos agir?}

A proposta final sugerida na cartilha é a elaboração de um projeto com caráter sociopolítico, permitindo que os alunos discutam em grupos e construam propostas de recuperação da lagoa mais próxima da escola, ou aquela que acreditam estar em um estado de maior degradação. O professor de ciências poderá realizar esse trabalho com os alunos conforme as discussões realizadas em sala e com os professores de outras disciplinas. Esse projeto com caráter interdisciplinar possibilitará que os alunos tenham uma visão ampliada a partir da orientação sob a ótica de outras áreas de conhecimentos. É interessante que esse projeto seja apresentado em um evento na escola que seja aberto à comunidade, de modo que os estudantes sejam os protagonistas para a construção e discussão das possíveis soluções dos problemas ambientais da lagoa em questão.

Revbea, São Paulo, V.16, № 5: 27-45, 2021.

revista brasileira

educação ambiental 
Nesse evento da escola é interessante a presença dos órgãos ambientais de Feira de Santana-BA e a entrega do projeto escrito a essas entidades, para servir de base para o planejamento e práticas ambientais desses órgãos municipais. Essa ação, permite que os alunos se sintam como sujeitos ativos de uma sociedade melhor, e compreendam de fato a importância social desse trabalho.

O trabalho realizado em grupo desenvolve competências e habilidades de relação social que contempla uma aprendizagem por meio da interação proposta por Vigostsky (1991). Promove também, uma educação seguindo a pedagogia de Paulo Freire, que considera que educar é um ato de conhecimento da realidade concreta, e os temas geradores contribuem para uma educação libertadora. As lagoas de Feira de Santana tornam-se temas geradores no ensino e, contribuem para esse modelo de educação pautada na construção de valores e atitudes onde o aluno se vê como sujeito sociopolítico.

Ausubel (1980) apud Vasconcelos et al. (2003) afirmam, que os alunos processam as informações nas suas estruturas cognitivas de dois modos, mecanicamente ou de forma significativa. A aprendizagem significativa corresponde a um processo interno e pessoal, em que o aluno relaciona uma informação nova com um aspecto relevante da estrutura de conhecimento dele, ou seja, com conceitos já existentes (subsumer). Ausubel pontua na sua abordagem de aprendizagem os organizadores prévios, que correspondem aos elementos introdutórios que devem ser apresentados antes do material de aprendizagem. Estes, transmitem ideias mais gerais servindo como ponte entre o que o aluno já sabe com a informação nova, ou seja, os organizadores prévios funcionam como pontes cognitivas que facilitam a aprendizagem e, essa parte prática proposta na cartilha, terá um grande significado.

\section{Conclusões}

Este estudo permitiu a investigação de teorias de aprendizagem e análise dos Parâmetros Curriculares Nacionais e da Base Nacional Comum Curricular que embasam os currículos da educação básica. Essas pesquisas fundamentaram as propostas de Educação Ambiental envolvendo as lagoas de Feira de Santana, de modo a elaborar um material didático, na forma de cartilha, que dialogue com o ensino de ciências neste contexto.

As lagoas possuem uma relação íntima com a constituição da história de Feira de Santana, elas têm sua importância ambiental, histórica, cultural e social e que deve ser considerada no ensino de ciências. Tratar as lagoas como um tema gerador para se discutir os problemas ambientais no conteúdo de ciências, é uma abordagem contextual que permite uma aprendizagem mais significativa. Trabalhar desse modo, perpassando outras áreas de conhecimento, permite também uma educação interdisciplinar, sendo esta necessária para que o aluno não construa seu conhecimento de forma fragmentada. 
Com esse material paradidático espera-se que ele tenha caráter continuativo no sentido de despertar interesse de outros pesquisadores em aplicar e testar a viabilidade das propostas, e assim aperfeiçoá-las. Para então, servir como material de auxílio para os professores de ciências e biologia de Feira de Santana, e assim contribuir para a educação do município.

\section{Referências}

ABÍLIO, F.J.P. Ética, Cidadania e Educação Ambiental. In: ANDRADE, M.O. (org.). Meio Ambiente e Desenvolvimento: bases para uma formação interdisciplinar. João Pessoa, PB: Editora Universitária da UFPB, 2008.

ANA. Agência Nacional de Águas. Relatório Atlas Esgoto. 2017. Disponível em: <http://atlasesgotos.ana.gov.br/>. Acesso: 10 Abr 2021.

BRASIL, Resolução n. 357, de 17 de março de 2005. Classificação dos corpos de água e diretrizes ambientais para o seu enquadramento, bem como estabelece as condições e padrões de lançamento de efluentes. Diário Oficial da União. Brasília, DF, 18 mar. 2005.

BRASIL. Identidades da Educação Ambiental brasileira. Brasília: Ministério do Meio Ambiente, 2004. 156 p.

BRASIL. Ministério da Educação e Desporto. Secretaria da Educação Fundamental. Parâmetros Curriculares Nacionais: Meio Ambiente (terceiro e quarto ciclo do ensino fundamental). 1998. Disponível em: $<$ http://portal.mec.gov.br/seb/arquivos/pdf/ciencias.pdf>. Acesso em 23 Jan. 2018.

BRASIL. Ministério da Educação. Base Nacional Comum Curricular. BNCC (terceira versão). Dezembro, 2017. Disponível em: $<$ http://basenacionalcomum.mec.gov.br/images/BNCC El EF 110518 versaofi nal site.pdf>. Acesso em 15 Mai. 2019.

CAMARGO, D. O ensino da Educação Ambiental através da ludicidade: atividades lúdicas para os anos iniciais do ensino fundamental. Anais... In: Fórum Internacional de Pedagogia, Santa Maria, Rio Grande do Sul, 8 p. 2014.

CAPRA, F. A teia da vida: uma nova compreensão científica dos sistemas vivos. Editora Cultrix: São Paulo, 2006, 249 p.

FEIRA DE SANTANA. Lei no 3.326, de 05 de junho de 2012. Aprova o plano municipal de educação de Feira de Santana, e dá outras providências. Leis Municipais, 26 Mar. 2013.

FREIRE, P. Pedagogia da autonomia. São Paulo: Paz e Terra, 1996.

IBGE. Instituto Brasileiro de Geografia e Estatística. População estimada Feira de Santana. 2021. Disponível em: <https://www.ibge.gov.br/cidades-eestados/ba/feira-de-santana.html>. Acesso em 15 Jul 2021. 
IVIC, I. Lev Semionovich Vygostsky: ensaio. Recife: Editora Massangana, 2010.

JACOBI, P. Educação Ambiental, cidadania e sustentabilidade. Cadernos de pesquisa. Março, 2003, n. 118, p. 189-205

LAYRARGUES, P.P. Educação para a Gestão Ambiental: a cidadania no enfrentamento político dos conflitos socioambientais. In: LOUREIRO, C.F.B., LAYRARGUES, P.P.; CASTRO, R. S. de (orgs). Sociedade e Meio Ambiente: A Educação Ambiental em Debate. São Paulo: Cortez, 2000.

LEITE, A.E.B. Simulação do lançamento de esgotos domésticos em rios usando um modelo de qualidade d'água, SisBAHIA. 2004. 94f. Dissertação (mestrado em Saúde Pública) - Escola Nacional de Saúde Pública, Fiocruz, Rio de Janeiro, 2004.

LOBÃO, J.S.B.; MACHADO, R.A.S. Avaliação multi-temporal, da ocupação das Lagoas urbanas de Feira de Santana-BA, por meio de Sistema de Informação Geográfica. Anais... In: XII Simpósio Brasileiro de Sensoriamento Remoto, Goiânia. Abr, 2005.

MACHADO, M.F.R.C.; MATOS, E.L.M. O planejamento e uso dos recursos didáticos tecnológicos no apoio às aulas expositivas. In: FERREIRA, J.L. (Org.). Formação de Professores: Teoria e Prática Pedagógica. Petrópolis, RJ: Vozes, 2014. p. 148-170.

MARTINS, L.; SANTOS, G.S.; EL-HANI, C.N. Abordagens de saúde em um livro didáticos de biologia largamente utilizado no ensino médio brasileiro. Investigações em ensino de ciências, v.17, n.1, p.249-283, 2012.

NASCIMENTO, G.M. et al. A cartilha como instrumento de apoio didático: uma abordagem sobre os invertebrados da caatinga. Revista brasileira de Educação Ambiental, v.15, n.6, 17-51, 2020.

NETO, J.M.; FRACALANZA, H. O livro didático de ciências: problemas e soluções. Ciência e Educação, v.9, n.2, p. 147-157, 2003.

NUNES, V.J. 2012. 44f. Determinação de metais pesados (Mn, Cd, Cr, Cu, Pb) em espécies de peixes presentes na Lagoa Salgada - Feira de Santana. Monografia (Graduação em Ciências Biológicas) - Universidade Estadual de Feira de Santana, Feira de Santana, 2012.

OLIVEIRA, A.J.; et al. Coliformes termotolerantes: bioindicadores da qualidade da água destinada ao consumo humano. Atas de Saúde Ambiental, v.3, p. 2429, 2015.

OLIVEIRA, D.K.; ANTUNES, M.S.; SOARES, B.M. Saída de campo: atividade que possibilita explorar uma diversidade de conteúdos no meio ambiente. Anais... In: II Congresso Internacional de Educação Científica e Tecnológica, Santo Angelo, 2012.

PERONI, N.; HERNÁNDEZ, M.I.M. Ecologia de populações e comunidades. Florianópolis: CCB/EAD/UFSC. 125p. 2011. 
PRIMACK, R.B.; RODRIGUES, E. Biologia da conservação. Editora Planta. 327p. 2001.

PRUDÊNCIO, C.A.; GUIMARÃES, F.J. A contextualização no ensino de ciências na visão de licenciandos. Anais... In: XI Encontro Nacional de Pesquisa em Educação em Ciências, Universidade Federal de Santa Catarina, Florianópolis, SC, 2017.

RABELO, R.C.; GUTJAHR, A.L.N.; HARADA, A.Y. Metodologia do processo de elaboração da cartilha educativa "O papel das formigas na natureza", Enciclopédia Biosfera, Centro Científico Conhecer, v.11, n.21, p. 2769-2777, 2015.

REIGOTA, M. O que é Educação Ambiental. Editora Brasiliense. 112p. 2001.

SANTO, S.M. O desenvolvimento urbano em Feira de Santana, Sitientibus, v.1, n.28, p. 9-20, 2003.

SANTOS, J.D. et al. Artes plásticas e Educação Ambiental: uma reflexão e sensibilização interdisciplinar. Revista monografias ambientais, v.14, n.1, p.123-135, 2015.

SCHALL, V.T.; DINIZ, M. C. P. Information and Education in Schistosomiasis Control; an Analysis of the situation in the State of Minas Gerais, Brazil. Memórias do Instituto Oswaldo Cruz, Rio de Janeiro, v. 96, p. 35-43, 2001.

VASCONCELOS, C.; PRAIA, J.F.; ALMEIDA, L.S. Teorias de aprendizagem e o ensino/aprendizagem das ciências: da instrução à aprendizagem. Psicologia escolar e educacional, v.7, n.1, p. 11-19, 2003.

VIVEIRO, A.A.; DINIZ, R.E.S. As atividades de campo no ensino de ciências: reflexões a partir das perspectivas de um grupo de professores. In: NARDI, R. (org.) Ensino de ciências e matemática. São Paulo: Cultura Acadêmica, 258p. 2009.

VYGOSTSKY, L. A formação social da mente. $4^{\text {a }}$ ed. São Paulo, Martins Fontes, 1991.

VYGOSTSKY, L. A formação social da mente: o desenvolvimento dos processos superiores. São Paulo, Martins Fontes, 1988.

ZABALA, A. A prática educativa: como ensinar. Porto Alegre: Artmed. 224p. 1998. 